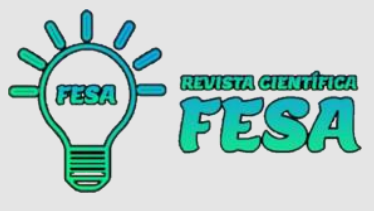

Jul. 2021

v. 1, n. $6,63-84$

ISSN: $2676-0428$

\title{
DESAFIOS E POSSIBILIDADES DA FORMAÇÃ̃O DOCENTE COMO CONDICIONANTES DE QUALIDADE NA EDUCAÇÃO A DISTÂNCIA
}

\author{
Luciana Casagrande Aragão ${ }^{1}$
}

\begin{abstract}
RESUMO
A formação de profissionais da educação constitui-se em uma das exigências do mundo globalizado, sendo um tema presente nos grandes debates na área educacional. Assim, este trabalho teve como objetivo central identificar os desafios e as possibilidades da formação docente como elementos condicionantes de qualidade na educação a distância. Para tanto, utilizaram-se como referências, sobre a formação de professores e a educação a distância, os autores Alarcão (2001), Imbernón (2001), Moran (2009), Nóvoa (1991, 1992, 1995), Prado (1991), Preti (2000), Kenski (2009), entre outros. Dessa forma, atrelada à concepção de mudança do paradigma, diante deste novo mundo globalizado, está justificativa deste estudo que é a compreensão de que o papel do profissional de educação na atualidade é o de estimular os alunos a aprenderem a buscar e a selecionar as fontes de informação disponíveis para a construção do conhecimento, sabendo selecioná-las, analisá-las e reelaborá-las, sendo esses saberes aprendidos por meio de formações continuadas. Espera-se, com o presente artigo, fornecer uma nova contribuição para a seara científica, tendo em vista a constante necessidade de se investir tanto nas formações docentes, quanto na qualidade da educação.
\end{abstract}

Palavras-chave: Formação Docente; Educação a Distância; Formação Continuada.

\section{RESUMEN}

La formación de profesionales de la educación es una de las demandas del mundo globalizado, siendo un tema presente en los grandes debates en el ámbito educativo. Así, este trabajo tuvo como objetivo identificar los desafíos y posibilidades de la formación docente como condicionantes de la calidad en la educación a distancia. Para ello, los autores Alarcão (2001), Imbernón (2001), Moran (2009), Nóvoa (1991, 1992, 1995), Prado (1991), Preti (2000), Kenski (2009), entre otros fueron utilizados como referencias sobre formación docente y educación a distancia. Así, ligado a la concepción del cambio de paradigma, ante este nuevo mundo globalizado, se justifica este estudio, que es el entendimiento de que el papel del profesional de la educación hoy en día es animar a los estudiantes a aprender a buscar y seleccionar las fuentes de información disponibles para la construcción del conocimiento, sabiendo cómo seleccionarlas, analizarlos y reelaborarlos, y estos conocimientos se aprenden a través de formaciones continuas. Se espera, con este artículo, aportar una nueva contribución al área científica, en vista de la constante necesidad de invertir tanto en la formación del profesorado como en la calidad de la educación.

Palabras clave: Formación del Profesorado; Educación a Distancia; Educación Permanente.

\section{ABSTRACT}

The training of education professionals is one of the demands of the globalized world, being a theme present in the great debates in the educational area. Thus, this work aimed to identify the challenges and possibilities of teacher education as conditioning elements of quality in distance education. For this, the authors Alarcão (2001), Imbernón (2001), Moran (2009), Nóvoa (1991, 1992, 1995), Prado (1991), Preti (2000), Kenski (2009), among others were used as references

\footnotetext{
${ }^{1}$ Mestre em Ciências da Educação pela Universidad USAL - Argentina Pedagogia - Supervisão Escolar

Diretora do Centro Estadual de Educação de Jovens e Adultos de Linhares. centrolinhares@sedu.es.gov.br
}

\section{Multifaces do Conhecimento Científico: Teoria e Prática}




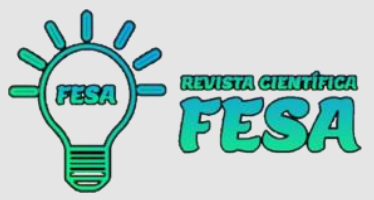

on teacher training and distance education. Thus, tied to the conception of paradigm change, in view of this new globalized world, this study is justified, which is the understanding that the role of the education professional today is to encourage students to learn to seek and select the sources of information available for the construction of knowledge, knowing how to select them , analyze them and rework them, and these knowledges are learned through continuous formations. It is expected, with this article, to provide a new contribution to the scientific area, in view of the constant need to invest both in teacher training and in the quality of education.

Keywords: Teacher Training; Distance Education; Continuing Education.

\section{INTRODUÇÃO}

As mudanças sociais, políticas, econômicas, culturais e tecnológicas ocorridas na sociedade repercutem na educação escolar e no trabalho docente impondo novas demandas educativas. A formação de profissionais da educação, especialmente para atuação na docência da educação básica, constitui-se em uma das exigências do mundo globalizado, sendo um tema presente nos grandes debates na área educacional.

Nota-se que a globalização trouxe transformações, não apenas no âmbito econômico, mas também nas relações sociais, impondo novos padrões de comportamentos e conceitos referentes à família, à escola, ao consumo, à cultura, à arte e às formas de pensar e de compreender a vida em sociedade.

Assim, as exigências e as expectativas que se colocam, atualmente, para a escola e para o professor são inúmeras, o que acaba por gerar um desconforto, um mal estar ou uma "tensão" nos professores que não se sentem "competentes" o suficiente para assumirem todos os papéis que lhes são impostos por pressões de ordem interna (conflitos pessoais, sentimentos de autolimitação, diminuição da autoestima) e de ordem externa (pressão da instituição escolar, das determinações e normas do Ministério de Educação e das Secretarias de Educação, participação em projetos de gestão da escola, dentre outros).

A sociedade e a escola se veem pressionadas diante de novos modelos organizacionais que emergem no mundo do trabalho, com o desenvolvimento das tecnologias da comunicação e informação e a disseminação de informações e conhecimentos, demandando uma constante atmosfera formativa que lida com diversos entraves que precisam ser identificados e, posteriormente, evitados.

Portanto, o presente artigo tem a meta de identificar os desafios e as possibilidades da formação docente como elementos condicionantes de qualidade

\section{Multifaces do Conhecimento Científico: Teoria e Prática}

Periódico Multidisciplinar da Facility Express Soluções Acadêmicas - ISSN: 2676-0428 


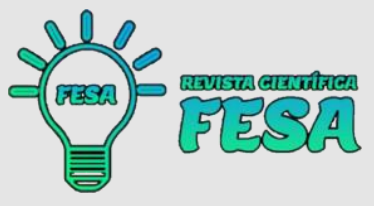

na educação a distância. Dessa maneira, os postulados presentes neste estudo se organizam em torno dos seguintes eixos: Condicionantes de Qualidade para a Formação Docente; Formação inicial; Formação continuada; Formação continuada dos professores para uso das TICs; Educação a Distância e Considerações Finais.

\title{
CONDICIONANTES DE QUALIDADE PARA A FORMAÇÃO DOCENTE
}

O ofício dos professores, no início do processo de escolarização, gozava de status, sendo uma profissão de prestígio social. O professor possuía autonomia e controle sobre o seu trabalho docente. Com o processo de expansão do ensino e a ampliação do acesso de uma maioria à escola, ocorreu um processo de deterioração dos espaços escolares e um aumento das expectativas em relação à função do professor.

Pimenta (2002) constatou que, no mundo contemporâneo, o crescimento quantitativo dos sistemas de ensino não tem correspondido a um resultado formativo, ou melhor, qualitativo, adequado às exigências da população envolvida, nem às exigências das demandas sociais, passando a exigir uma nova identidade profissional do professor.

Nacarato et al. (2003) destaca algumas das expectativas em relação ao trabalho docente, afirmando que:

\begin{abstract}
Espera-se que este (a), além do domínio do conteúdo que leciona e das estratégias relacionadas ao ato pedagógico - saber conduzir uma aula, como facilitador(a) e dinamizador(a) da aprendizagem, explorar dinâmicas de grupo, garantir a disciplina, saber avaliar, etc.- exige-se também dele(a) que seja animador(a), pedagogo(a) eficaz, e desempenhe funções que vão além do ensino: cuidar do equilíbrio emocional, afetivo e psicológico dos estudantes, da integração social, da higiene pessoal, da educação sexual, etc. (NACARATO et al., 2003).
\end{abstract}

Diante de tantas atribuições e responsabilidades o professor se sente impotente profissionalmente, principalmente, levando-se em consideração as frágeis condições de trabalho em nosso país. São várias as contradições presentes na prática do professor, e que influenciam no processo de aprendizagem. Sobre isso, Soares (2006, p. 65) afirma que:

\section{Multifaces do Conhecimento Científico: Teoria e Prática}


O desafio imposto à Educação neste início de século XXI é a busca por uma modernização da estrutura escolar: procuram-se novas metodologias, novas abordagens e conteúdos cognitivos. A reformulação e a ressignificação passam por um ajuste na formação docente, mais sintonizada com as mudanças de nossa época e com a utilização de novas formas de expressão. (SOARES, 2006, p. 65).

Chiapinni (2005, p. 278), discorrendo sobre a importância da formação do professor, afirma que:

\begin{abstract}
A formação do professor é fator imprescindível para que a escola consiga melhorar a capacidade do cidadão comunicante, uma vez que o professor pode adotar em sua prática cotidiana uma postura que subsidia e estimula o aluno a refletir sobre o que significa comunicar-se em nossa sociedade, como também aprender a manipular tecnicamente as linguagens e a tecnologia. (CHIAPINNI, 2005, p. 278).
\end{abstract}

Nas últimas décadas do século XX, educadores, legisladores, estudiosos, instituições e governos manifestaram opiniões sobre a formação de professores. De acordo com Neto et al. (2007), a LDB n. 4024/61 questionou o modelo de currículo que vinha sendo adotado nos cursos de Licenciatura, passando a exigir um currículo mínimo, composto por um núcleo de matérias com vistas a uma adequada formação cultural e profissional com ênfase na formação do educador.

O Artigo 67, inciso IV da LDB, postula que a formação continuada constitui um dos aspectos fundamentais da valorização dos profissionais da educação aos quais é assegurada a progressão funcional baseada na titulação ou habilitação e na avaliação do desempenho. Dessa forma, compreende-se que, se a formação prévia adequada é imprescindível à competência profissional daqueles que atuam na educação, sendo a formação continuada essencial para o crescimento constante dos profissionais, como cidadãos e como pessoas.

Macedo $(2014$, p. 4) nos alerta sobre a importância da articulação entre a formação inicial e continuada, uma vez que a primeira não pode ser entendida como um fim em si mesmo, capaz de oferecer todo um conjunto de conhecimentos, habilidades e atitudes necessárias para o exercício da profissão docente. Ela deve ser vista como uma etapa do processo de formação profissional do professor, cuja função seria a de oferecer uma bagagem sólida de conhecimentos teóricos que favoreçam o desenvolvimento do trabalho docente.

Levando-se em consideração a importância do processo de formação dos professores para o desenvolvimento das atividades docentes e para a melhoria

\title{
Multifaces do Conhecimento Científico: Teoria e Prática
}

Periódico Multidisciplinar da Facility Express Soluções Acadêmiças - ISSN: 2676-0428 
da qualidade na educação, abordaremos, a seguir, os processos de formação inicial e continuada de professores.

\title{
FORMAÇÃO INICIAL
}

As discussões sobre a formação de professores são recorrentes no cenário educacional, não apenas no Brasil, mas em vários outros países, principalmente em função das mudanças no mercado de trabalho, que demanda, também, mudanças nas políticas públicas, inclusive no processo de formação continuada.

Ao discorrer sobre a formação de professores, Cruz e Monteiro (2005, p. 37) afirmam que:

\begin{abstract}
O desafio de formar professores no Brasil deve ser enfrentado em diversos níveis. Um passo fundamental é assegurar que todos os educadores de Educação Básica tenham formação em nível superior objetivo já preconizado na Lei de Diretrizes e Bases, de 1996. Cerca de $25 \%$ dos professores brasileiros nessas etapas da escolaridade ainda possuem, no máximo, o Ensino Médio ou Magistério. Além do esforço necessário para graduar os educadores, na visão dos especialistas, é necessário também aprimorar com urgência a qualidade da formação, tanto nos cursos de Pedagogia como nas licenciaturas. (CRUZ; MONTEIRO, 2005, p. 37).
\end{abstract}

É nesse quadro de novos desafios para a educação escolar que a formação de professores vem sendo objeto de estudo, nas instituições de ensino superior e nos órgãos governamentais, visando à melhoria da qualidade do sistema de ensino. Sobre isso, Macedo (2014) assevera que:

\begin{abstract}
Mas muitas críticas têm sido feitas a maneira como a formação de professores tem sido operacionalizada em nosso país e um conjunto significativo de reflexões e propostas vem sendo elaboradas, visando elevar a formação profissional do professor ao nível superior, transformar a estrutura do ensino e da carreira, melhorar a qualidade da formação, além de outros aspectos específicos de cada eixo da formação docente (inicial e/ou continuada). (MACEDO, 2014, p. 3).
\end{abstract}

Então, o processo educativo ocorre em situações cotidianas que se caracterizam pela singularidade e pelos problemas que ocorrem na prática e que requerem reflexão dos professores, o que requer a busca de soluções específicas para cada caso.

\section{Multifaces do Conhecimento Científico: Teoria e Prática}


Ghedin et al. (2008, p. 31) afirmam que a formação de professores deve possibilitar ao profissional docente o domínio do processo formativo dos alunos em suas várias dimensões, além da cognitiva, englobando a dimensão afetiva, educação dos sentidos, da estética, da ética e dos valores.

Macedo (2014), citando Imbernón (2006, p. 41), enfatiza a importância da formação inicial oferecida aos professores e afirma, ainda, que ela não prepara os docentes para desenvolverem novas metodologias e não oferece embasamento para que o professor possa desenvolver, implantar e avaliar processos de mudança.

Dessa forma, faz-se necessário questionar a formação desses professores em suas licenciaturas, já que os cursos de formação inicial, não tem propiciado um embasamento teórico consistente aos futuros docentes. Gonçalves (2007), citando Schon (2001, p. 114), afirma que os cursos de licenciatura seguem o modelo da "racionalidade técnica", em que os conteúdos específicos das disciplinas são ministrados antes dos conteúdos pedagógicos, sendo que esses últimos, em geral, são ministrados no final dos cursos. Esse modelo parte do entendimento de que o professor, conhecendo a parte teórica, poderá dominar meIhor a técnica, ou seja, as estratégias/procedimentos de aprendizagem, tornando-se, dessa forma, melhor instrumentalizados para a solução de problemas.

O que se observa é uma grande fragilidade desses cursos, que não propiciam a integração entre teoria e prática, verificando-se que os elementos teóricos estudados ao longo do curso estão desconectados dos desafios existentes no âmbito do sistema escolar, não favorecendo a compreensão sobre o trabalho pedagógico pelos docentes.

Diante da complexidade do processo de ensino e aprendizagem e levandose em consideração que a Pedagogia, como um ramo das Ciências Humanas, não se refere apenas ao domínio técnico, ou à escolha certa de meios e procedimentos, como pode ocorrer na área das Ciências Exatas, pode-se apreender que as relações e fenômenos que caracterizam esse saber "têm como características a complexidade, a incerteza, a instabilidade, a singularidade e envolvem conflitos de valores" (GONÇALVES, 2007 apud PÉREZ GÓMEZ, 2001, p. 114). 


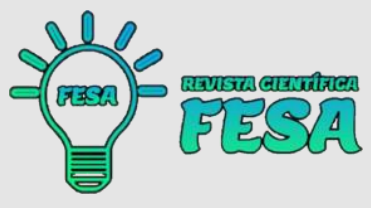

Imbernón (2006, p. 41) esclarece que a formação inicial é um momento importante, pois caracteriza o início do processo de profissionalização. Para o autor, diante do contexto de novas demandas para o trabalho docente:

[...] O professor precisa de novos sistemas de trabalho e de novas aprendizagens para exercer sua profissão [...] a formação será legitima então quando contribuir para o desenvolvimento profissional do professor no âmbito de trabalho e de melhoria das aprendizagens profissionais. (IMBERNÓN, 2006, p. 41)

O educador Paulo Freire (1996) se referia à formação como um fazer permanente que se refaz constantemente na ação. Faz parte da carreira do professor buscar uma formação continuada que the possibilite sua inserção na estrutura sociopolítica, cultural e econômica, uma vez que, não basta dominar o conteúdo específico de sua área, nem tampouco as formas de transmiti-lo, pois o contexto atual exige uma formação ampla, que implica na conexão do professor com a sociedade, buscando compreensão dos problemas e soluções para essas questões abrangentes.

\section{FORMAÇÃO CONTINUADA}

A formação continuada de docentes é um tema complexo e que pode ser abordado a partir de diferentes enfoques. Essa formação não se apresenta como um conceito muito claro, sobretudo, porque abarca, também, todas as iniciativas de formação realizadas após a Formação Inicial, como cita Garcia (1999):

[...] A Formação de Professores é a área de conhecimento, investigação e de propostas teóricas e práticas que, no âmbito da Didática e da Organização Escolar, estuda os processos através dos quais o professores - em formação ou em exercício - se implicam individualmente ou em equipe, em experiências de aprendizagem através das quais adquirem ou melhoram os seus conhecimentos, competências e disposições, e que thes permite intervir profissionalmente no desenvolvimento do seu ensino, do currículo e da escola, com o objetivo de meIhorar a qualidade da educação que os alunos recebem. (GARCIA, 1999, p. 26).

A educação contínua ou continuada corresponde a um processo de formação constante, que implica em aprender sempre, aprender em serviço, procurando associar teoria e prática, refletindo sobre a própria experiência e ampliando-a com novas informações e relações. (MORAN, 2002).

\section{Multifaces do Conhecimento Científico: Teoria e Prática}




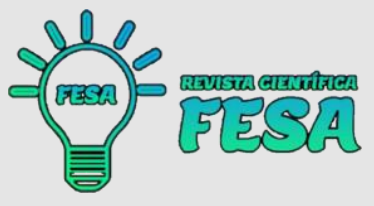

A formação continuada dos docentes é justificada pela necessidade de "inovação" do campo educacional, nos documentos legais da década de 90 e início do ano 2000, considerado tardio em relação ao contexto mundial. (BRASIL, 1999; 2005).

A base legal para institucionalização da Formação Continuada está amparada na Lei de Diretrizes e Bases da Educação (LDB) n. 9304/96, cujo inciso III, do art. 63, afirma que as instituições formativas deverão manter programas de formação continuada para os profissionais de educação dos diversos níveis e cujo inciso II, do art. 67, estabelece que os sistemas de ensino deverão promover aperfeiçoamento profissional continuado, inclusive com licenciamento periódico remunerado para esse fim.

A publicação de documentos como a LDB n. 9394/96 (BRASIL, 1996a), os Referenciais de Formação de Professores - RFP (BRASIL, 1999) e as Diretrizes Gerais da Rede Nacional de Formação Continuada de Professores - RNFC (BRASIL, 2005) refletem a importância que a formação continuada dos professores da educação básica tem ocupado nas políticas públicas no país.

A Lei $n$. 9394/96 determina que todos os educadores sejam qualificados adequadamente nos planos acadêmicos e pedagógicos, para que sejam capazes de responder às necessidades e desafios que lhe são apresentadas.

No documento intitulado "Referenciais para Formação de Professores" do MEC, encontramos a definição e as diretrizes para o desenvolvimento de ações de formação continuada:

\begin{abstract}
É necessidade intrínseca para os profissionais da educação e faz parte de um processo permanente de desenvolvimento profissional que deve ser assegurado a todos. A formação continuada deve propiciar atualizações, aprofundamento das temáticas educacionais e apoiar-se numa reflexão sobre a prática educativa, removendo um processo constante de autoavaliação que oriente a construção contínua de competências profissionais. Porém, um processo de reflexão exige predisposição a um questionamento crítico da intervenção educativa e uma análise da prática na perspectiva de seus pressupostos. Isso supõe que a formação continuada se estenda às capacidades e atitudes e problematize os valores e as concepções de cada professor e da equipe (BRASIL, 1999, p. 70).
\end{abstract}

A Formação Continuada apoia-se, também, na Resolução n. 03/97, do Conselho Nacional de Educação (CNE), que define, no artigo 5ํㅜ que os sistemas de ensino envidarão esforços para implementar programas de desenvolvimento

\title{
Multifaces do Conhecimento Científico: Teoria e Prática
}




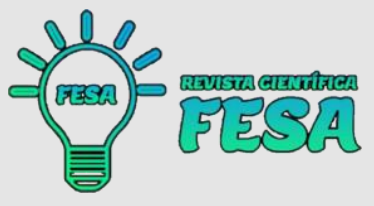

profissional dos docentes em exercício, incluída a formação em nível superior em instituições credenciadas, bem como em programas de aperfeiçoamento em serviço.

O MEC criou a base legal que institui um amplo programa nacional de formação continuada de professores, visando à qualificação pedagógica da ação docente, tendo em vista garantir uma aprendizagem efetiva, condizente com os fins da educação escolar e com o efetivo direito à educação e à escola de qualidade (BRASIL, 2006).

Dessa forma, as ações de formação continuada no Brasil são recentes. As primeiras sistematizações dos órgãos públicos, voltados ao aperfeiçoamento do pessoal docente, com o planejamento de cursos para os docentes, têm início em meados da década de 60 e início da década de 70, inclusive pelo Ministério da Educação (MEC). (PALMA FILHO; ALVES, 2003)

Em meados da década de 70 e 80, iniciou-se o trabalho de treinamento e formação permanente junto aos professores, voltado para o que se denominava na época, como "ensino de primeiro grau" no Brasil. Os cursos funcionavam sob a forma representativa, ou seja, alguns poucos professores participavam das formações e depois "repassava" essa mesma formação aos demais docentes das escolas em que atuavam.

Essa técnica de formação teve grande influência no modo de desempenhar ações de formação contínua para professores no país, pois acreditava-se que esse tipo de formação alcançava eficácia para a parcela de professores participantes destes "treinamentos", que uma vez capacitados, seriam capazes de capacitar os demais profissionais do ensino.

No início da década de 90, o país passa por um intenso processo de diminuição das ações do Estado, sob influência das políticas neoliberais, orientadas por acordos internacionais, que refletiram, também na área educacional:

\footnotetext{
A formação continuada de educadores no país ganhou mais legitimidade com a publicação dos Referenciais para Formação de Professores (RFP) (BRASIL, 1999), documento elaborado pelo MEC e publicado em fins da década de 90 . Apesar de ser uma referência legal importante, ele deixa em aberto um aspecto central da formação continuada dos professores - erro anteriormente cometido pela LDB 9394/96 (BRASIL, 1996a) _ referente às ações e ao perfil dos sujeitos formadores; embora seja reconhecido o papel central que os formadores têm
}

\section{Multifaces do Conhecimento Científico: Teoria e Prática}


na concretização da formação continuada. (GALINDO; INFORSATO, 2007, p. 103).

Analisando os Referenciais para Formação de Professores (BRASIL, 1999, p. 46), os autores verificaram que o próprio documento realiza duas críticas principais no que se refere à administração, organização e metodologia da formação continuada, alegando que elas demonstram dificuldades na gestão:

[...] Falta de articulação entre várias instâncias de gestão do sistema, a descontinuidade dos projetos e programas de um governo para outro, a pressa com que as ações são planejadas e realizadas para atender às limitações do tempo político das administrações, a falta de incentivos salariais ou institucionais para que os professores participem de programas de formação e a inexistência de tempo previsto na jornada de trabalho e no calendário escolar para formação em serviço [...] não se planeja de forma articulada ações extensivas e de profundidade, priorizando-se a alternativa de grandes eventos pontuais, cujo efeito é bastante relativo e discutível [...] não há como considerar suas reais necessidades e avanços em atividades desse tipo. (GALINDO; INFORSATO, 2007, p. 104).

Deste modo, a formação continuada dos professores, não ocorre a contento, pois não há um acompanhamento contínuo da prática pedagógica, nem avaliação periódica dos resultados obtidos com as formações, o que requer uma tomada de decisão acerca dos objetivos da formação continuada para os anseios de uma sociedade em mudança.

Percebe-se que as práticas voltadas à formação dos professores sofrem influência do contexto histórico, político, econômico e social, com reflexos nos saberes docentes, no conhecimento específico, nos aspectos didáticos ou nas dimensões políticas e ideológicas, um processo que não leva em consideração a participação e a reflexão coletiva.

A formação continuada deve, dentre outros objetivos, propor novas metodologias, abrir espaços para que os profissionais da educação se coloquem a par das discussões teóricas atuais, visando sempre contribuir para as mudanças que se fazem necessárias para a melhoria da ação pedagógica na escola e consequentemente na educação, pois conceber novas teorias é fator essencial para o processo de construção profissional. Soares (2006, p. 16) afirma que:

O desafio imposto à Educação neste início de século XXI é a busca por uma modernização da estrutura escolar: procuram-se novas metodologias, novas abordagens e conteúdos cognitivos. A reformulação e a ressignificação passam por um ajuste na formação docente, mais

\section{Multifaces do Conhecimento Científico: Teoria e Prática}


sintonizada com as mudanças de nossa época e com a utilização de novas formas de expressão (SOARES, 2006, p. 16).

Para Candau (1999), o modelo clássico de formação continuada para docentes baseia-se em iniciativas de renovação pedagógica. A ênfase é dada na atualização da formação recebida ou numa "reciclagem", que para ela significa "refazer o ciclo".

Na visão de Prada (1997), os termos empregados para nomear os programas de formação continuada de professores estão impregnados da concepção filosófica que orienta o processo, recebendo também influências da região, país e instituições envolvidas, entre outros fatores.

Costa (2004), citando vários estudiosos, afirma que no modelo clássico:

[...] O professor que já atua profissionalmente, com sua formação inicial, volta à universidade para renovar seus conhecimentos em programas de atualização, aperfeiçoamento, programas de pós-graduação lato sensu e stricto sensu, ou ainda, participando de cursos, simpósios, congressos e encontros voltados para seu desenvolvimento profissional. Esse modelo, em geral, é promovido pelas Secretarias de Educação, a que docentes estão vinculados ou por outras entidades na área (COSTA, 2004, p. 38).

De acordo com Costa (2004), a ênfase é dada na atualização da formação recebida ou numa "reciclagem" que significa "refazer o ciclo". Nesse modelo, privilegiam-se os espaços considerados como lócus da produção do conhecimento, como: a universidade e os demais espaços vinculados a ela, pois se considera que a universidade é o local em que circulam as informações mais recentes, as novas tendências e buscas nas mais diferentes áreas do conhecimento. Alguns autores criticam essa visão por não considerarem as escolas de Ensino Fundamental e Médio como produtoras de conhecimento.

As pesquisas na área têm confirmado que esse modelo clássico é o que vem sendo praticado nos sistemas educacionais para a formação continuada dos profissionais do magistério.

A oferta de cursos de especialização por meio de convênios entre instituições universitárias e secretarias de educação, é uma prática comum. Esses cursos são realizados em regime presencial ou na modalidade a distância. No Brasil, várias universidades estão criando cursos de aperfeiçoamento de 


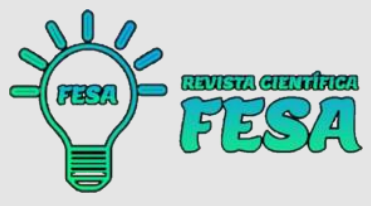

Jul. 2021

v. 1, n. $6,63-84$

ISSN: $2676-0428$

professores nesta modalidade, não só para a rede pública, como também para a rede privada de ensino.

Uma outra modalidade de formação continuada, na perspectiva tradicional, são as ações promovidas por órgãos responsáveis pelas políticas educacionais como, Secretarias de Educação dos estados e municípios e/ou o próprio Ministério de Educação, ofertando cursos de caráter presencial ou a distância:

\begin{abstract}
Além dos cursos promovidos de natureza presencial, insere-se também nessa modalidade programas de formação continuada a distância como os veiculados pela TV Escola, que se constitui numa formação aberta a todas as escolas públicas que possuam antena parabólica, receptor, TV e vídeo. O programa é vinculado ao Ministério da Educação e coordenado em todos os Estados pelas respectivas Secretarias de Educação. Embora estas iniciativas possuam características do modelo clássico, apresentam condições de ser trabalhada numa perspectiva de práticas inovadoras, onde as escolas se assumam enquanto lugares de formação como um exemplo vivo desse aspecto da interface. (COSTA, 2004).
\end{abstract}

Costa (2004) classifica a formação continuada de professores, em quatro estilos ou categorias, a saber:

\begin{abstract}
A forma universitária, que tem como finalidade a transmissão dos saberes teóricos. Tem características semelhantes à dos profissionais liberais-clientes, por ter caráter voluntário e pela relação constituída entre formador-formando, os mestres são produtores do saber e o aluno funciona como receptor dos conhecimentos. A forma escolar, onde estão organizados todos os cursos através de um poder legítimo, exigem escolaridade obrigatória e existe uma instância organizadora onde os formadores não são responsáveis pelo programa nem por decisões administrativas. Possuem um papel passivo em termos de planejamento. (COSTA, 2004, p. 126).
\end{abstract}

Costa (2004) afirma que nesta concepção Demailly (2004) destaca significativa diferença entre as formas universitária (parece ser mais eficiente no plano individual) e interativo-reflexiva (mais eficiente nos planos individual e coletivo porque suscita menor resistência por parte dos professores). Essa segunda permite, para a autora, respostas aos problemas vivenciados, aborda a prática de maneira global e permite a criação de novos saberes para a profissão. E continua dizendo que:

A forma contratual, que se caracteriza pela negociação entre os diferentes parceiros. Estes estão ligados por uma relação de troca ou contratual do programa pretendido, modalidades materiais e ações pedagógicas da aprendizagem. A forma interativo-reflexiva, bastante presente nas iniciativas de formação voltadas para a resolução de problemas reais. Nessa modalidade, está presente uma ajuda mútua entre

\title{
Multifaces do Conhecimento Científico: Teoria e Prática
}


formandos e uma ligação à situação de trabalho (COSTA, 2004, p. 126).

Outros autores, como Nóvoa (1997) e Alarcão (2003) defendem a forma interativo-reflexiva como uma maneira organizada e produtiva no processo ensino-aprendizagem, conforme afirma Novóa (1991, p. 89).

As práticas voltadas para a formação dos professores devem permitir que eles reflitam e produzam, tanto os seus saberes, como seus valores, em um processo participativo de reflexão coletiva. Macedo (2014), citando Alarcão (2003), Imbernón (2006) e Libâneo e Pimenta (1999), afirma que:

[...] A formação continuada se insere no processo de formação docente não como um mecanismo de substituição ou complementação da formação inicial, mas como um elemento que contribuirá para a atuação profissional do docente. Ela não consiste, apenas, em um processo de atualização científica, didática ou pedagógica, mas deverá fornecer elementos que possibilitem o professor a repensar o seu fazer pedagógico, por meio do desenvolvimento de atitudes que lhe permitam descobrir, fundamentar, organizar, revisar e construir saberes, os quais contribuirão para a melhoria do seu desempenho profissional. (MACEDO, 2014, p. 124).

Percebemos, assim, que a abordagem sobre a formação de professores, envolve a adoção de múltiplas perspectivas. Nessa abordagem podemos destacar duas tendências interpretativas predominantes: uma centrada na análise de seus componentes, valorizando o conhecimento prévio necessário; outra na valorização da prática profissional refletida como fonte primeira, valorizando o conhecimento emergente da prática e da reflexão sobre ela.

O exercício da função docente deve propiciar condições de refletir na, e sobre a sua prática, no intuito de que essa formação transcorra ao longo de toda a trajetória do ato de educar, pois, como esclarece Perrenoud (1993), o ato de ensinar não se restringe a aplicar cegamente uma teoria, nem se contentar com um modelo, sobretudo, implica na resolução de problemas, na tomada de decisões, no agir em situações indeterminadas e muitas vezes emergentes.

Levando em consideração que o conhecimento é uma relação que se estabelece entre a prática e as interpretações que fazemos da mesma, a reflexão sobre a ação constitui o questionamento da própria prática e, um questionamento efetivo, inclui intervenções e mudanças. Dessa forma, o profissional prático reflexivo é alguém que age com a convicção de estar acertando e, se não acertar,

\section{Multifaces do Conhecimento Científico: Teoria e Prática}

Periódico Multidisciplinar da Facility Express Soluções Acadêmicas - ISSN: 2676-0428 
tem a humildade de, após refletir sobre seus atos, retomar o erro como uma forma de aprendizagem individual.

Para Contreras (2002), a reflexão é um processo coletivo, uma vez que o professor não se constitui como profissional reflexivo sozinho, mas em interação com outras pessoas, pois o professor está inserido em um contexto educacional que envolve a instituição na qual atua e seus pares, com os quais conversa e compartilha experiências.

Nóvoa (1997, p. 26) não privilegia, em sua análise, a perspectiva acadêmica, mas adota uma perspectiva centrada no aspecto profissional, pessoal e de organização, a partir do contexto escolar. Ele alerta que a formação de professores tem ignorado o desenvolvimento pessoal, confundindo "formar e formarse".

Para Nóvoa (1998), todo processo de formação deve ter como referencial o saber docente, o reconhecimento e valorização desse saber. Dessa forma, as ações de formação continuada devem levar em consideração as etapas de desenvolvimento profissional do docente, ou seja, seus aspectos psicossociais. Existem grandes diferenças de anseios e necessidades entre o docente em fase inicial, o que já adquiriu uma considerável experiência pedagógica e o que já se encaminha para a aposentadoria.

Tardif (2002) sustenta que a subjetividade dos professores, enquanto atores e sujeitos do conhecimento deve ser o foco das pesquisas referentes ao ensino e à escola.

Alarcão (2003, p. 100) afirma que a formação continuada deve, dentre outros objetivos, propor novas metodologias, abrir espaços para que os profissionais da educação se coloquem a par das discussões teóricas atuais, visando sempre contribuir para as mudanças que se fazem necessárias para a melhoria de ação pedagógica na escola e, consequentemente, na educação, pois conceber novas teorias é fator essencial para o processo de construção profissional.

Entretanto, essas teorias não são suficientes, se não possibilitarem ao professor um saber que o leve a as relacionar com seu conhecimento prático, construído no dia a dia, sabendo adequá-las às necessidades impostas pelas mudanças de paradigmas, pelo avanço tecnológico, pelas novas descobertas cientificas e pela evolução dos meios de comunicação.

\section{Multifaces do Conhecimento Científico: Teoria e Prática}




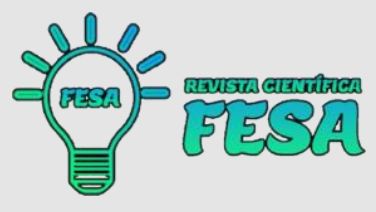

Concordamos com Imbernón (2006) sobre a complexidade da formação continuada dos professores e que essa formação não pode ser desenvolvida apenas no âmbito das escolas, pois:

[...] O professor não deve refletir unicamente sobre sua prática, mas sua reflexão atravessa as paredes da instituição para analisar todo tipo de interesses subjacentes à educação, à realidade social, com o objetivo concreto de obter a emancipação das pessoas. (IMBERNÓN, 2006).

Tornar-se professor, segundo Pacheco (1995, p. 45):

[...] É um processo dinâmico e evolutivo que compreende um conjunto variado de aprendizagens e de experiências ao longo das diferentes etapas formativas, em um processo de transformação e reconstrução, de aprendizagem contínua de caráter formal ou não formal, que vai além da aquisição de conhecimentos e destrezas, constituindo uma questão de individualidade. (PACHECO, 1995, p. 45).

No sentido de destacar a importância da formação continuada de professores para uso das tecnologias na educação e para o desenvolvimento da EAD, consideramos importante destacar o conceito de "educomunicação", que tem sido objeto de estudos e pesquisas, realizadas no final dos anos 90 , por especialistas de toda a América Latina, países ibéricos e Estados Unidos. A definição de Educomunicação, encontrada em artigo de Soares (2002, p. 55) é aquela que:

\begin{abstract}
Designa um conjunto de ações voltadas para a criação de ecossistemas comunicativos abertos e criativos em espaços educativos, favorecedores tanto de relações dialógicas entre pessoas e grupos humanos quanto de uma apropriação criativa dos recursos da informação nos processos de produção da cultura e da difusão do conhecimento. $O$ novo campo apresenta-se como interdiscursivo, interdisciplinar e mediado pelas tecnologias da informação. (SOARES, 2002, p. 55).
\end{abstract}

Assim, no caso da EAD, o conceito de educomunicação assume importância para as mediações tecnológicas, conforme trataremos no tópico a seguir.

\title{
EDUCAÇÃO A DISTÂNCIA
}

O uso das tecnologias no processo educacional envolve maior complexidade no fazer pedagógico do professor que precisa ter disponibilidade para apropriar-se dessa tecnologia e ser capaz de desenvolver uma metodologia com seus alunos. Isso implica a necessidade de atualização e formação permanente do

\section{Multifaces do Conhecimento Científico: Teoria e Prática}

Periódico Multidisciplinar da Facility Express Soluções Acadêmictas - ISSN: 2676-0428 


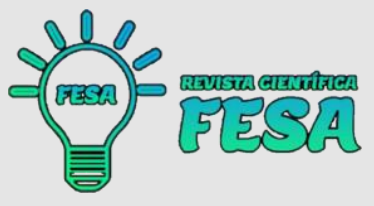

professor. Não basta ao professor "aprender" a utilizar o computador e a internet, se ele não for capaz de desenvolver formas criativas de empregá-la, de experimentar novas práticas e de mudar a forma de se relacionar com o conhecimento e com os alunos. De acordo com Demo (1996, p. 200):

[...] A teleducação não dispensa o professor, embora agregue a seu perfil outras exigências cruciais, como saber lidar com materiais didáticos produzidos com meios eletrônicos, trabalhar em ambientes diferentes daqueles formais da escola ou da universidade, acompanhar ritmos pessoais, conviver com sistemáticas diversificadas de avaliação (DEMO, 1996, p. 200).

Os professores que atuam na educação a distância precisam desenvolver várias habilidades, uma vez que o trabalho docente na EAD se diferencia do trabalho docente presencial em função de características inerentes a essa modalidade, como: o redimensionamento do espaço e tempo, o uso das tecnologias digitais de informação de comunicação, a necessidade de formação permanente, de adaptação, de flexibilidade, o respeito ao ritmo de aprendizagem dos alunos, a construção de autonomia para o estudo. Outra característica que diferenciará uma modalidade de ensino da outra são os autores envolvidos nesse processo e a organização do trabalho. De acordo com Oliveira (2008, p. 207):

\begin{abstract}
A função docente virtual transforma o professor indivíduo em professor coletivo, representado por uma equipe de trabalho formada por profissionais de distintas áreas de atuação (webdesigner, programador, designer instrucional, especialista em conteúdo, especialista em linguagem audiovisual, roteirista, pedagogo, psicólogo etc.), cuja constituição depende das características requeridas pela concepção, pelo desenvolvimento e pelo aperfeiçoamento de determinado projeto formativo (OLIVEIRA, 2008, p. 207).
\end{abstract}

Além das atividades realizadas pelos alunos e acompanhadas pelos tutores é indispensável que os cursos de capacitação continuada a distância ofereçam oportunidades para que as pessoas se aproximem e interajam umas com as outras, possibilitando o compartilhamento, a colaboração e a interação, vivenciando um sistema colaborativo e cooperativo:

$O$ fato de na EAD virtual o ensino poder ser conduzido por intermédio das TIC (Tecnologias da Informação e Comunicação) tornam-no um desafio para a maioria dos professores que precisam substituir os modos de interação tradicionais e descobrir o potencial destas tecnologias para o processo de ensino-aprendizagem, o que nas palavras de Moore et al (2008), se dá através da humanização da relação, cujas

\title{
Multifaces do Conhecimento Científico: Teoria e Prática
}


técnicas para alçá-la varia de acordo com a tecnologia. (MACHADO; SANTOS, 2010, p. 42).

A interação na EAD virtual difere dos modos anteriores a essa geração, pois, graças às tecnologias, a comunicação tornou-se multidirecional (e não apenas unidirecional e bidirecional como anteriormente). Na atualidade, os ambientes virtuais de aprendizagem dispõem de uma diversidade de formas de comunicação síncronos e assíncronos, que ocorrem por meio de chats, fóruns, emails, telefonemas e, inclusive, encontros presenciais.

A incorporação das TIC no âmbito escolar, precisa estar inserida em uma política educacional ampla, levando em consideração a demanda social, carente de informações sobre o valor real da inserção das tecnologias como recurso propiciador de inovações pedagógicas a serviço da construção de saberes. Para que isso ocorra, faz-se necessário o desenvolvimento de ações voltadas à formação permanente dos docentes (long life learning), para que possam acompanhar o acelerado processo de desenvolvimento científico e tecnológico (DELORS, 1998). O mundo contemporâneo exige modificações significativas no papel do professor. Nesse processo, é imprescindível a intervenção do Estado:

Para que a aprendizagem a distância se efetive, não basta somente contratar mais professores, oferecer materiais de estudo e usar tecnologias sofisticadas. É necessário um ambiente que favoreça o processo de ensino, com estratégias educativas baseadas no diálogo, nas interações promovidas pelo/a professor/a, gerando aprendizagens significativas. (FERREIRA, 2013, p. 190).

Muitos professores assumem uma postura diversificada e nem sempre favorável ao uso das tecnologias, por motivos diversos, implicando muitas vezes em uma mudança de comportamento radical dos professores. Ponte (1998) afirma que:

\footnotetext{
Alguns olham-nas com desconfiança, procurando adiar o mais possível o momento do encontro indesejado. Outros, assumem-se como utilizadores na sua vida diária, mas não sabem muito bem como as usar na sua prática profissional. Outros ainda, procuram integrá-las no seu processo de ensino usual, sem, contudo, alterar de modo significativo as suas práticas. Uma maioria entusiasta procura desbravar caminho, explorando constantemente novas possibilidades, mas defronta-se com muitas perplexidades. (PONTE, 1998, p. 10).
}

A tecnologia está tão presente em nosso cotidiano que, até mesmo aqueles que dizem não gostar de usar alguns recursos tecnológicos, de certa forma,

\section{Multifaces do Conhecimento Científico: Teoria e Prática}

Periódico Multidisciplinar da Facility Express Soluções Acadêmictas - ISSN: 2676-0428 


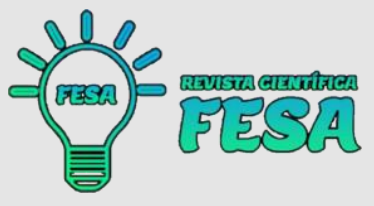

usam sem nem mesmo perceberem, basta ir ao supermercado, ou a uma instituição bancaria para nos deparamos com a presença de vários aparatos tecnológicos. Nesse sentido, a educação escolar precisa se adequar às essas necessidades. Soares (2006) afirma que:

\begin{abstract}
O desafio imposto à Educação neste início de século XXI é a busca por uma modernização da estrutura escolar: procuram-se novas metodologias, novas abordagens e conteúdos cognitivos. A reformulação e a ressignificação passam por um ajuste na formação docente, mais sintonizada com as mudanças de nossa época e com a utilização de novas formas de expressão. (SOARES, 2006, p. 29).
\end{abstract}

O MEC vem implementando de forma sistemática, políticas para formação inicial e continuada de professores à distância. Em articulação com os sistemas de ensino e com o apoio da sociedade, tem trabalhado no sentido de ampliar 0 acesso da população escolarizável a todos os níveis e modalidades de ensino e de qualificar ainda mais a educação oferecida.

Em geral, as políticas públicas voltadas para a educação são executadas em regime de colaboração entre Estados, municípios e União. Esse regime está previsto no pacto federativo, enquanto princípio constitucional. O Ministério da Educação exerce funções: normativa, redistributiva e suplementar, coordenando e propondo políticas públicas educacionais em âmbito nacional.

Para que ocorra uma mudança pedagógica nas escolas, não basta apenas a introdução dos computadores na escola, mas sim investir na formação dos educadores, pois não se trata de criar condições para o professor simplesmente dominar o computador ou o software, mas sim auxiliá-lo a desenvolver conhecimento sobre o próprio conteúdo e sobre como o computador pode ser integrado no desenvolvimento desse conteúdo.

\title{
CONSIDERAÇÕES FINAIS
}

Vimos que o professor, independente da modalidade educativa em que atue, precisa se readaptar constantemente para saber lidar com diversas situações, das quais lhe é exigido o desempenho de novas funções. A introdução das TIC nas escolas provoca um processo de desestruturação na metodologia de ensino baseada na hegemonia do livro didático e na fragmentação do conhecimento.

\section{Multifaces do Conhecimento Científico: Teoria e Prática}




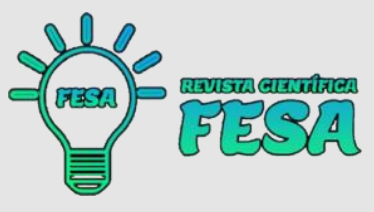

Alguns professores descobriram as potencialidades das novas mídias e as integraram às suas metodologias de ensino e mídias tradicionais. Entretanto, muitos profissionais do ensino enfrentam a resistência natural dos indivíduos para as mudanças, decorrendo a necessidade de formação continuada para o uso das tecnologias, uma vez que a maioria dos professores não teve a oportunidade de utilizá-las em seu processo de formação inicial.

Kenski (2003) nos alerta para o fato de que o novo contexto da sociedade implica em mudanças que se caracterizam pela alteração nos papéis dos professores e das escolas, bem como nas condições e oportunidades de ensino; ampliação das possibilidades de aprendizagem em espaços formais e não-formais, com tempos e lugares diferenciados (modalidade presencial e a distância); envolvimento de todos para a construção da produção individual e coletiva dos conhecimentos.

Assim, elencam-se como desafios a fragilidade desses cursos de formação inicial ou continuada, uma nova postura institucional que requer uma nova tomada de decisão acerca dos objetivos da formação inicial e continuada para os anseios de uma sociedade em mudança, e uma reconfiguração formativa, já que a atual não leva em consideração a participação e a reflexão coletiva. Uma possível solução seria a proposição de novas metodologias a fim de abrir espaços para que os profissionais da educação se coloquem a par das discussões teóricas atuais

\section{REFERÊNCIAS BIBLIOGRÁFICAS}

ALARCÃO, Isabel (Org.). Escola reflexiva e nova racionalidade. Porto Alegre: Artmed, 2001.

ALARCÃO, Isabel. Professores reflexivos em uma escola reflexiva. 6. ed. São Paulo: Cortez, 2008.

BRASIL. Lei no. 9.394, de 20 dez. 1996. Estabelece as Diretrizes as Diretrizes e Bases da Educação Nacional. Diário Oficial da União, Brasília, DF, 23 dez. 1996.

BRASIL. Ministério de Educação e Cultura. Secretaria de Educação Fundamental. Referenciais para Formação de Professores. Brasília, 1999.

\section{Multifaces do Conhecimento Científico: Teoria e Prática}




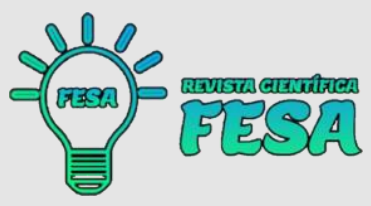

BRASIL. Decreto n. 5.622, de 19 de dezembro de 2005. Regulamenta o art. 80 da Lei $n$ 9.394, de 20 de dezembro de 1996, que estabelece as diretrizes e bases da educação nacional. Brasília, 2005.

CANDAU, Vera Maria Ferrão. Formação continuada de professores: tendências atuais. In: REALI, A. M.; MIZUKAMI, M. da G. (Org.). Formação de professores: tendências atuais. S. Carlos, SP, 1996.

CHIAPINNI, L. A reinvenção da catedral. São Paulo: Cortez, 2005.

CONTRERAS, J. A autonomia de professores. São Paulo: Cortez, 2002.

COSTA, N. M. de L. A formação contínua de professores - Novas tendências e Novos Caminhos. RN. 2004. Disponível em:

http://www2.ifrn.edu.br/ojs/index.php/HOLOS/article/viewFile/48/52. Acesso em: 20 out. 2011.

CRUZ, P.; MONTEIRO, L. (Org.) Anuário Brasileiro da Educação Básica. São Paulo: Editora Moderna, 2013.

DELORS, Jacques et al. Educação: um tesouro a descobrir. 8 ed. São Paulo: UNESCO/ Cortez, 2000. Adaptado do Relatório para a UNESCO da Comissão Internacional sobre Educação para o Século XXI.

DEMAILLY, L. C. Modelos de formação contínua e estratégias de mudança. In: NÓVOA, Antonio (Org.). Professores e sua formação. Lisboa: Dom Quixote, 1992.

FERREIRA, S. R. A Docência na EAD. In: Seminário Internacional de Educação a Distância, 5. Anais ... Juiz de Fora: CAED, UFMG, 2013.

FREIRE, Paulo. Pedagogia da Autonomia: Saberes Necessários à Prática Educativa. 23. ed. Rio de Janeiro: Paz e Terra, 1996.

GARCIA, C. M. Formação de professores para uma mudança educativa. Portugal: Porto Editora, 1999.

IMBERNÓN, F. Formação Docente e Profissional: Formar-se para a mudança e a incerteza. 3. ed. São Paulo: Cortez, 2002. (Coleção Questões da Nossa Época: v. 77).

LIBÂNEO, J. C.; PIMENTA, S. G. Formação de profissionais da educação: Visão crítica e perspectiva de mudança. Revista Educação \& Sociedade, v. 20, n. 68, dez. 1999.

MACHADO, G. J. C.; SANTOS, R. M. dos. A didática online: propostas e desafios. Revista Scientia Plena, Sergipe, UFS, v. 6, n. 7, 2010.

MACEDO, V. P. Formação de Professores no Contexto das Mudanças Educativas. Disponível em:

\section{Multifaces do Conhecimento Científico: Teoria e Prática}




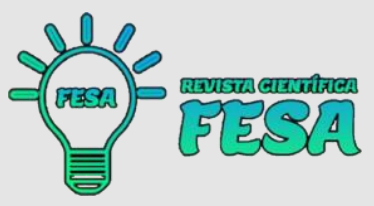

http://www.anpae.org.br/simposio2011/cdrom2011/PDFs/trabalhosCompletos/comunicacoesRelatos/0525.pdf . Acesso em: 9 jul. 2014.

MORAN, J. M. O que é educação à distância. 2002. Disponível em: <http://www.eca.usp.br/prof/moran/dist.htm>. Acesso em: 22 ago. 2013.

NACARATO, A. M.; VARANI, A.; CARVALHO, V. de. OCotidiano do trabalho docente: palco, bastidores e trabalho invisível... abrindo as cortinas. In: GERALDI, M. G.; FIORENTINI, D.; PEREIRA, E. M. de A. P. (Org.). Cartografias do trabalho docente. Campinas: Mercado de Letras, 2003. p.73-104.

NÓVOA, Antonio. Concepções e práticas da formação contínua de professores: In: NÓVOA, A. (Org.). Formação contínua de professores: realidade e perspectivas. Portugal: Universidade de Aveiro, 1991.

NÓVOA, Antonio.Os professores e sua formação. 2. ed. Lisboa: Dom Quixote, 1995.

NÓVOA, Antônio. Professores imagens do futuro presente. Lisboa: EDUCA, 2009.

OLIVEIRA, Sidnei. Geração Y: Era das Conexões, tempo de Relacionamentos. São Paulo: Clube de Autores, 2009.

OLIVEIRA, R. M. Falando de criatividade. In: Formação contínua de professores. NETTO, L. et al. Graduações a distância e o desafio da qualidade.

2010. Disponível em: <http://www.pucrs.br/edipucrs/graduacoes.pdf>. Acesso em: 20 abr. 2011.

PÉREZ GÓMEZ, Angel L. Qualidade do ensino e desenvolvimento profissional docentecomo intelectual reflexivo. Rio Claro: UNESP, v. 3, n. 1, 1997. Disponível em: http://www.rc.unesp.br/. Acesso em: 19 jul. 2014.

PERRENOUD, Philippe. Dez novas competências para ensinar. Trad. de Patrícia Chittoni Ramos. Porto Alegre: Artmed, 2000.

PIMENTA, S. G.; GHEDIN, Evandro (Org.). Professor reflexivo no Brasil: gênese e crítica de um conceito. São Paulo: Cortez, 2002.

PONTE, João P. Tecnologias de informação e comunicação na formação deprofessores: Que desafios? Dísponivel em: http://www.campus-oei.org/revista/rie24a03.htm. Acesso em: 25 fev.2014.

SCHÖN, D. Educando o profissional reflexivo: um novo design para o ensino e aprendizagem. Porto Alegre: Artmed, 2000.

SOARES, M. S. P. Comunicação, Linguagens e Tecnologias no Cotidiano Escolar, 2006. Dísponivel em: http://132.248.9.34/hevila/PerCursosFlorianopolis/2006/vol7/no1/4.pdf. Acesso em: 5 abr. 2014.

\section{Multifaces do Conhecimento Científico: Teoria e Prática}


TARDIF, M. Saberes docentes e formação profissional. Rio de Janeiro: Vozes, 2002. p. 31-55. 